\title{
ENSAIO DE ÉPOCAS DE TRANSPLANTE PARA 0 FUMO
}

\author{
F. G. Brieger, A. Rodrigues Lima, \\ R. Forster, A. S. Costa e \\ S. Ribeiro dos Santos
}

\section{INTRODUÇÃO}

As plantações de fumo no Estado de São Paulo são usualmente atacadas por diversas moléstias, entre as quais se encontra a conhecida por "vira-cabeça" (5). A percentagem de infeção de "vira-cabeça" é variavel de região para região, assumindo uma importância relativa (3).

Nas regiões onde os nossos ensaios foram realizados, essa moléstia assume carater de acentuada gravidade, motivando a importância d̀ mesma atribuida no presente estudo.

Meios práticos de combate à moléstia ainda não foram encontrados. Daí ressalta a importância da procura de meios de controle com variedades resistentes e a escolha de épocas menos favoraveis à sua disseminação, como medidas profiláticas. Com essa finalidade realizamos um ensaio, associando variedades e épocas de transplante, cujos resultados aquí apresentamos. Representam três anos de observações, e, se bem não tenha o ensaio decorrido satisfatoriamente, apresentou, todavia, diversas indicações de valor prático, o que motivou esta publicação.

\section{EXECUÇ̃̃O DO ENSAIO}

O ensaio foi realizado nos anos agrícolas de 1937/38, 1938/39 e 1939/40, nas seguintes Estações Experimentais: Campinas, Limeira, Piracicaba e Tietê.

Variedades : As variedades empregadas formam parte da coleção do Instituto Agronômico e estão em cultivo há já alguns anos.

No ano agrícola 1937/38 utilizamos para o ensaio dez variedades, cujos números e nomes na coleção são os seguintes: Virgínia Bright (V-1), Amarelinho (V-33), Chinês (V-68), Rio Branco (V-73), Rio Pardinho (V-75), Talo Branco (V-121), Sumatra (V-141), Samsoun (V-142), Ambalema (Nolla "strain" da Colômbia) (V-147) e Kentucky (V-164). 
Para os dois anos agrícolas seguintes reduzimos a seis o número de variedades, substituindo ainda três das anteriores, ficando o ensaio com as seguintes variedades: Virgínia Bright (V-1), Kentucky (V-14), Amarelinho (V-33), Barker's Sumatra (V-38), Goiano (V-70) e Samsoun ( $\mathrm{V}-142)$.

Parcela "standard" : Em 1937/38 utilizamos uma parcela "standard" com 30 plantas, abrangendo uma área de $29,46 \mathrm{~m}^{2}$ e, nos outros dois anos, uma parcela com 48 plantas em $39,46 \mathrm{~m}^{2}$.

Barreiras : Visando dificultar a disseminação de moléstias de uma variedade para outra, empregamos barreiras de separação entre os canteiros. Utilizamos, em 1937/38, o milho em três das Estações Experimentais e o gergelim (Sesamum indicum L.), em Piracicaba. $O$ primeirc se mostrou impróprio, devido ao ciclo vegetativo curto em relação ac tempo de duração do ensaio, e o segundo, por se ter mostrado hospedeiro de um inseto (Thrips sp.) da ordem Thysanoptera. Como a esta ordem pertence o vetor de "vira-cabeça" (2) poderia tal inseto ser tambem outro vetor da moléstia. Nos anos seguintes empregamos a Crotalaria juncea L., que mostrou ser boa barreira.

Deixamos de comentar as vantagens do uso de barreiras, pois isso só seria possivel com dados colhidos por entomologista sobre a infestação de insetos, principalmente os dos gêneros Thrips e Frankliniela, entre os quais se encontram vetores de "vira-cabeça" (2).

Em outro ensaio que estamos efetuando, deixamos de utilizar barreiras de separação, porquanto, pelo que nos foi dado observar, parece não serem elas de muita eficácia, para o caso presente.

Épocas : $\bigcirc$ plano inicial consistia em se fazerem as plantações em intervalos regulares de um mês e, simultaneamente, nas quatro Estações Experimentais. Mas isso, em geral, não foi possivel, em virtude, às vezes, de atraso no desenvolvimento das mudas, outras vezes, por infeção, no viveiro, por moléstias de dificil controle, como consequência, geralmente, de tempo muito úmido. Desse modo, tambem o número de épocas em que finalmente foram executadas não era o mesmo nos ensaios, paralelamente. No quadro 1 assinalamos todas as datas de transplante, agrupadas por maior proximidade de tempo, sendo feitas muitas considerações sob essa base.

Semeação: As semeações foram sempre realizadas em número de três para cada época, em caixas de madeira, empregando-se terra esterilizada (7). As semeações para cada época eram feitas com intervalo de cinco dias, uma da outra. Os desbastes foram feitos normalmente. As 
pulverizações com calda bordalesa, arseniatos, sulfato de nicotina, foram executadas sempre que necessário e, tambem, preventivamente.

Plantação: Foi realizada pelas normas usuais (6), quanto a métodos de adubação, irrigação e tratos culturais. Pulverizações das plantas no campo foram efetuadas sempre que necessário. Replantas foram realizadas até dez dias após o transplante.

Anotações : Observações no campo foram feitas para moléstias que mais comumente ocorrem nas plantações de fumo no Estado, isto é, "vira-cabeça", mosaico (") do fumo, "necrose branca-couve" e "leafcurl". Aquí, porem, as considerações serão apenas para "vira-cabeça". As anotações que deveriam ter sido tomadas cada quinze dias, nem sempre o foram, devido à falta de pessoal habilitado em número suticiente, alem de outras dificuldades surgidas na ocasião das anotações.

"Stand" : $\bigcirc$ "stand" médio inicial, isto é, depois de bem pegadas as mudas nos seus lugares definitivos, foi, em geral, bastante reduzido em confronto com o número de indivíduos plantados, que foi de 30 , em $1937 / 38$, e de 48 , nos outros anos.

Para se calcular a percentagem de infeção de "vira-cabeça" foi necessário excluir, do número inicial de plantas, todas as falhas e plantas mortas por causa desconhecida, ou conhecida, que não fosse a moléstia em apreço. Em consequência da irregularidade das anotações, muitas vezes, não foi possivel distinguir as plantas mortas por causas desconhecidas das mortas por "vira-cabeça". Em consequência, é provavel que, em alguns casos, o "stand" real seja superior ao usado no cálculo, e a percentagem de plantas doentes tambem maior que a computada.

\section{PLANO EXPERIMENTAL E ANÁLISE ESTATÍSTICA}

O plano experimental foi, em princípio, o mesmo nos quatro lugares e durante os três anos. Havia sempre três repetições completas, nas quais as épocas eram distribuidas ao acaso. Dentro das épocas, as parcelas das variedades foram distribuidas tambem ao acaso.

Assim, os sub-blocos continham, por época, em 1937/38, 10 parcelas, numa área de $300 \mathrm{~m}^{2}$, e nos outros dois anos, 6 parcelas numa área de $237 \mathrm{~m}^{2}$.

$\mathrm{Na}$ análise, entra, como variaveis, a percentagem de plantas doentes por parcela. Os quatro lugares e três anos foram tratados separadamente.

(*) Como mosaico foram incluidos tanto o produzido pelo Nicotiana virus 1 como o de Cucumis virus l, pela impossibilidade da distinção entre ambos, em campo. 
Os cálculos seguiram o caminho normal, com uma pequena correção. Em vista do "stand" médio muito variavel, foram usados valores compensados, multiplicando todos os quadrados pelo número das plantas ("stand"), fazendo-se depois uma divisão correspondente na soma dos quadrados e nos termos de correção. Em alguns casos, o número de plantas doentes foi relativamente pequeno, de modo que elas deviam seguir uma distribuição de Poisson. Porem, para não tratar diferentes partes da experiência de modo diverso, aquí tambem foram usadas as percentagens. Pela mesma razão e para não complicar desnecessariamente o cálculo, não foi aplicada a transformação angular das percentagens, de acordo com o método de Fischer e Yates (4).

$O$ resultado da decomposição dos erros totais consta dos quadros II a IV.

terreno foi aparentemente bastante homogêneo, como demonstra a componente correspondente nos quadros, designada "entre-repetições". Dos 12 valores de $\vartheta, 3$ foram fora do limite $1 \%$ e 1 estava entre os limites de 5 a 1\%. Entre eles 5 foram menores do que o erro residual e 7 maiores. As interações época-repetição e variedade-repetição tambem foram em geral insignificantes.

Uma comparação das médias gerais contidas na última linha dos quadros de decomposição (quadro II-IV), e na última parte dos quadros $\mathrm{V}$ a VII, demonstra que a infeção nos diferentes lugares e anos é bastante diferente. Enumerando os lugares em ordem crescente da infeção obtivemos a seguinte ordem :

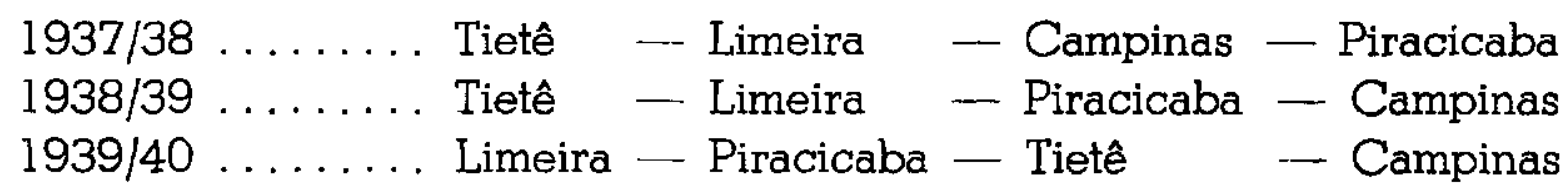

Não podemos dar uma explicação satisfatória sobre as causas das diferenças entre as quatro Estações Experimentais, uma vez que não temos elementos para atribuíllas às diversidades na composição dos solos, aliás muito acentuadas, à maior ou menor predominância de plantas hospedeiras, etc. Quanto ao clima e altitude, apresentam variações visiveis, porem não justificadoras de maiores efeitos. Em Campinas, pelo fato de ser a Estação Experimental mais antiga, há maior probabilidade de se terem acumulado focos de infeção.

Uma grande heterogeneidade notou-se com referência ds épocas. Todos os erros "entre-épocas", com apenas uma exceção, foram bem maiores do que o erro residual com valores esperados de acaso mais raramente do que 1 em 1000. Somente em um caso - Limeira 1937/38 
- este erro foi apenas insignificantemente maior do que seu erro residual; mas em se tratando de duas épocas somente, este valor de $\vartheta$ pequeno não tem importância.

As médias parciais por época e os seus respectivos erros da média constam dos quadros $\mathrm{V}$ a VII. É evidente que os valores não seguem uma certa ordem. Tomemos em consideração, por exemplo, o ano agrícola 1938/39, no qual o "stand" foi relativamente bom; vemos que em Campinas as primeiras épocas mostraram uma infeção bem maior do que as épocas mais tardias, quando, em Tietê, justamente as épocas do meio tínham a menor infeção. No ano de $1939 / 40$ a situação é quase inversa. Em Campinas, as primeiras épocas teem mais infeção do que as últimas. A maior infeção é encontrada nas épocas intermediárias.

Pensamos tentar, em virtude de bastante evidência sobre a influência dos fatores climatológicos, uma coordenação entre as chuvas e as variações da infeção nas épocas. Esta comparação, porem, não pode ser efetuada com bastante exatidão, em consequência da irregularidade das anotações.

Da mesma forma, como na comparação das quatro Estações Experimentais, tambem para as épocas não podemos dar nenhuma explicação das causas que afetam diferentemente a infeção, mas temos que nos limitar a constatar a existência da tais diferenças.

Passamos, finalmente, a comparar o comportamento das variedades. Dos 12 valores de $\vartheta$ correspondentes a erro "entre variedades" (quadro II-IV), 10 são fora do limite $1 \%, 1$ entre $1 \%$ e $1 \%$ e 1 entre $5 \%$ e $1 \%$. Evidentemente, a infeção nas variedades é bastante diferente, e estas diferenças são apenas pouco menos pronunciadas do que aquelas entre épocas.

As médias parciais por variedade constam na parte superior dos quadros V-VII, como tamberm os seus respectivos erros da média.

Para classificá-las com detalhe, foram calculados todos os valores de $\mathbf{t}$ correspondentes às diferenças destas médias parciais por variedade em relação às médias gerais (quadro VIII). A-pesar das diferenças constatadas entre os quatro lugares, reunimos tambem os valores por variedade para todos os lugares de um mesmo ano (6." coluna do quadro VIII).

Tomando em primeiro lugar estes valores de $\boldsymbol{t}$ como base, chegamos a distinguir três grupos com infeção diferente.

Em 1937/38 as variedades "Chinês" e "Amarelinho" foram as mais infetadas com valores de $\mathbf{t}$ para todas as localidades fora do limite $1 \%$. 
Para a primeira variedade, temos valores de $\mathbf{t}$ especialmente significantes em 3 das quatro Estações Experimentais.

Três outras variedades são, por sua vez, mais resistentes do que as demais: "Virgínia", "Ambalema" e "Samsoun", com valores de $t$ para todas as localidades fora do limite $1 \%$.

Nos outros dois anos foram usadas em parte as outras variedades. A classificação para estes dois anos é idêntica. Os valores de $\mathbf{t}$ mostram claramente que a variedade "Kentucky V 14" é menos resistente e a variedade "Sumatra V 38" bem mais resistente do que as outras quatro variedades que ocupam uma posição intermediária. A variedade "Virgínia", que era a mais resistente entre as variedades usadas em 1937/38, foi superada nos dois arros seguintes por "Sumatra" V 38.

$O$ teste de sequência, pela primeira vez aplicado por Brieger, Moreira e Leme (1), numa experiência com laranjas, foi aplicado tambem no caso presente e os resultados podem ser comparados com aqueles do $t$ - - teste. Os resultados são idênticos nos dois testes (últimas colunas do quadro VIII). As variedades ficam classificadas em 3 grupos, de acordo com a percentagem de plantas doentes.

A-pesar do resultado tão claro da análise estatística, o resultado prático é pequeno. A infeção na variedade mais resistente "Sumatra V 38" varia do mínimo de 0,4\% em Limeira, no ano de 1939/40, até ao máximo de $8,8 \%$ em Tietê, no mesmo ano, quando os valores para Campinas são 27,3\%, em 1939/40. Assim mesmo, esta variedade está bem longe de uma resistência completa.

Finalmente, podemos indagar se as variedades se comportam diferentemente nas diferentes épocas. Deixando Campinas de lado, com a sua infeção sempre muito grande, temos 8 valores de $\vartheta$ correspondentes à interação "época-variedade". Destes, dois apenas são significantes e os 6 restantes insignificantes. Considerando-se tambem a variação desordenada da infeção nas épocas, parece-nos pouco interessante entrar numa discussão detalhada das médias parciais, para melhor eșclarecer a natureza da interação nos dois casos significantes. É muito pouco provavel ser possivel chegar a conclusões definitivas e de importância prática.

\section{CONCLUSÃO}

Os resultados obtidos podem ser resumidos da seguinte forma :

1. Existem diferenças bem pronunciadas de infeção das plantas de fumo pelo virus de "vira-cabeça", nos três anos agrícolas de 1937/38, 
1938/39 e 1939/40, nas quatro Estações Experimentais (Campinas, Limeira, Piracicaba e Tietê) e nas diferentes épocas. As variações são de tal modo irregulares, que não podemos dizer qual região será mais indicada, ou qual a época mais apropriada para o melhor controle dessa moléstia.

2. A variedade "Sumatra $V 38$ " é definitivamente mais resistente do que as outras incluidas no ensaio. Deixando de lado Campinas, com sua infeção bastante grande, a percentagem de infeção varia entre 0,4 e $8,8 \%$ em $1939 / 40$ e entre 2,2 e $11,0 \%$ em 1938/39.

O valor prático desse resultado, porem, é bem diminuido pelo fato de ser esta variedade de pequena importância prática, em consequência do seu uso restrito a capas de charuto.

3. A variedade "Amarelinho V-33" que, pelos seus caracteres e pela coloração das folhas, parece muito indicada para ponto de partida da futura produção de fumos de cigarros em São Paulo (6) é das mais suscetiveis ao "vira-cabeça".

4. O que, enfim, podemos dizer a respeito da continuação da experiência ?

Da conclusão 1 podemos deduzir que será indicado procurar outras regiões onde haja menos focos de infeção. A respeito das épocas, a experiência realizada não deu indicação decisiva, mas, em vista de outras observações de ordem geral, parece indicado continuar-se a experiência, porem com maior número de épocas, com menores intervalos de tempo, estendendo-se sobre um maior espaço de tempo e com anotações mais acentuadas.

De acordo com a conclusão 2 podemos tentar, por métodos genéticos, combinar a resistência do "Sumatra" com os caracteres desejaveis de outras variedades produtoras de fumos claros, de utilidade para a fabricação de cigarros. Esse projeto já está sendo realizado, devendo, porem, decorrer vários anos antes da obtenção de resultados práticos.

Poderíamos estender futuramente a experiência a outras variedades de interesse, especialmente dentre as produtoras de fumos para cigarros, na proporção que as nossas observações assim recomendassem. Do material ora em vias de seleção, teremos por certo linhagens em todos os sentidos promissoras.

Poderíamos pensar tambem em estender mais tarde a experiência a outras variedades, especialmente dentro dos fumos claros. Não obstante, as nossas observações nas plantações de variedades da nossa co- 
leção não dão indicação de alguma cuja resistência iguale ou supere à do "Sumatra". Relativamente ao combate entomológico, parece-nos ainda o mais promissor. Novas e metódicas tentativas, para reduzir a expansão da moléstia por métodos de prevenção e combate aos insetos transmissores, poderão concorrer para o controle da moléstia.

\section{AGRADECIMENTOS}

Aos senhores chefes das Estações Experimentais de Limeira, Piracicaba e Tietê, nossos agradecimentos pela atenção que sempre dispensaram aos ensaios.

\section{SUMMARY}

1. Since our experiments on tobacco during the past years were greatly prejudiced by the extreme effect of the infection by the virus of the "vira-cabeça" causing the death of the great majority of the plants attacked, it was considered necessary to carry out an extensive experiment in order to determine whether there are differences: between localities, between varieties, between times of planting.

Thus the experiment was carried out during 3 years in four Experiment Stations in the State of São Paulo: (Campinas, Piracicaba, Tietê $\Theta$ Limeira). In the first year 10 varieties were included and later on their number was reduced to 6 . It was planed to sow and plant at regular time intervals and simultaneously in all Exp. Sta's, but this turned out to be impossible. Table 1 gives the dates of the transplanting actually carried out.

In each year and Exp. Sta., the plots containing one variety each were distributed within blocks at random and there were 3 complete replications of block.

Standard plots contained 30 plants in $29,92 \mathrm{~m}^{2}$ in $1937 / 38$ and 48 plants in $39,46 \mathrm{~m}^{2}$ during the other two years.

2. The disease "vira-cabeça" seems to be identical with "spotted wilt" and "kromneck" (2).

3. Very pronounced differences of the mean percentages of infection were established in different years, in the four Exp. Sta's and at different times. But these differences are without any evident order, and the time intervals were so irregular, they could not be put in contrast with meteorogical events. Consequently this part of the experiment has to be continued, and more detailed results are already available, but not yet fully analysed.

4. Differences between varieties are also quite evident and their significance was established both by the analysis of variance and the subsequent $t$-test as well as by the order test (1).

The variety Sumatra V 38 was definitely the most resistant. Leaving aside the results of Campinas where infection is always abnormaly high, the percentage of infected plants per plot varied between 0,4 and 8,8\% in 1939/40 and between 11,0 and 2,27 in 1938/39. Unfortunately the variety Sumatra is of no economical importance at the moment in São Paulo.

The variety Amarelinho $\mathrm{V} 33$, which according to its characters and the bright color of its leaves is indicated as one of the more important types for cigarette manufacture, belongs to the middle group with only slight resistance. 
5. The practical results of theses experiments may be briefly summarized as follows.

a) It seems indicated to transfer our work to regions were the ocurrence of "spotted wilt" is, at least so far, negligible.

b) The selection of the most favorable time of planting has to be ascertained in new experiments, which are already well under way. That the meteorogical conditions have a very great importance has been established beyond doubt.

c) There are no really resistant varieties. Experiments to transfer the relative resistance form Sumatra to bright tobaccos such as Amarelinho are under way.

d) It seems doubtfull whether the inclusion of more varieties will lead to the detection of a more resistant variety or strain.

e) But it seems especially indicated to estend the experiment in the future with the intention of finding an eficient way of combating the insects which transfer the disease.

\section{IITERATURA CITADA}

1. Brieger, F. G., S. Moreira $\Theta$ Z. Leme. Estudo sobre o melhoramento da laranja "Baía" III. Bragantia, 1 : 567-610. Figs. 1-10b. Quadros I-XIII. 1941.

2. Costa, A. S. e R. Forster. Identidade do virus de "vira-cabeça" e sua inclusão no grupo do virus do "spotted-wilt". Bragantia, 1 : 491-506. Figs. 1-19. 1941.

3. Costa, A. S. $\theta$ outros. Contribuição para o conhecimento da distribuição geográfica de moléstias de fumo, no Estado de São Paulo. Rev. Agricultura. Piracicaba. (Em publicação). 1942.

4. Fisher, R. A. e F. Yates. Statistical Tables for Biological, Agricultural and Medical Research, pgs. 1-90, Oliver and Boyd, London, 1938.

5. Forster, R. e A. S. Costa. Nota preliminar sobre a moléstia "vira-cabeça" do fumo. Rev. Agricultura. Piracicaba. 13 : 69-78. Fig 1-8. 1938.

6. Lims, A. Rodrigues. Cultura do fumo amarelo de estufa. Bol. Técn. do Instituto Agronômico do Estado de S. Paulo, 16: 1-43. Figs. 1-27. 1937.

7. Lima, A. Rodrigues. Instalação e tratamento do viveiro de fumo. Bol. Técn. do Instituto Agronômico do Estado de S. Paulo, 33: 1-20. Figs. 1-8. 1937. 


\section{QUADRO I}

\begin{tabular}{|c|c|c|c|c|c|}
\hline \multirow{4}{*}{$1937 / 38$} & CAMPINAS & LIMEIRA & PIRACICABA & TIETÊ & \\
\hline & \multicolumn{4}{|c|}{ Parcela de 30 plantas, com $29,92 \mathrm{~m}^{2}$} & \\
\hline & \multicolumn{2}{|c|}{10 variedades } & \multicolumn{2}{|c|}{3 repetições } & \\
\hline & $\begin{array}{l}26-X I-37 \\
20-X I I \\
17-I-38 \\
20-I I\end{array}$ & $\begin{array}{c}3-\mathrm{XI}-37 \\
\overline{17-\mathrm{I}-38} \\
-\end{array}$ & $\frac{\overline{-}}{6-\bar{I}-38}$ & $\begin{array}{l}19-X I-37 \\
15-X I I \\
15-I-38 \\
15-I I\end{array}$ & $\begin{array}{l}\text { A } \\
\text { B } \\
\text { C } \\
\text { D }\end{array}$ \\
\hline \multirow[t]{3}{*}{$1938 / 39$} & \multicolumn{4}{|c|}{ Parcela de 48 plantas, com $39,46 \mathrm{~m}^{2}$} & \\
\hline & \multicolumn{2}{|c|}{6 variedades } & \multicolumn{2}{|c|}{3 repetiç̃es } & \\
\hline & $\begin{array}{l}21-\mathrm{XI}-38 \\
27-\mathrm{XII} \\
\overline{-} \\
10-\mathrm{II}-39 \\
\overline{-} \\
10-\mathrm{IV} \\
29-\mathrm{V}\end{array}$ & $\begin{array}{l}24-\overline{X I I}-38 \\
\overline{30-I-39} \\
8-\text { II } \\
\text { I-III } \\
13-\text { III } \\
=\end{array}$ & $\begin{array}{c}18-X I-38 \\
13-X I I \\
9-I-39 \\
- \\
\overline{-I I I} \\
27-I I I \\
= \\
-\end{array}$ & $\begin{array}{l}29-X I-38 \\
26-X I I \\
- \\
23-I-39 \\
- \\
26-I I \\
27-I I I \\
16-I V \\
-\end{array}$ & $\begin{array}{l}\text { A } \\
\text { B } \\
\text { C } \\
\text { D } \\
\text { E } \\
\text { F } \\
\text { G } \\
\text { H } \\
\text { I }\end{array}$ \\
\hline \multirow[t]{3}{*}{$1939 / 40$} & \multicolumn{4}{|c|}{ Parcela de 48 plantas, com $39,46 \mathrm{~m}^{2}$} & \\
\hline & \multicolumn{2}{|c|}{6 variedades } & \multicolumn{2}{|c|}{3 repetições } & \\
\hline & $\begin{array}{l}\text { 1-XII-39 } \\
2-I-40 \\
8-I I \\
1 \text { I-III } \\
15-I V\end{array}$ & $\begin{array}{l}30-X I-39 \\
2-I-40 \\
25-I \\
11-I I I \\
-\end{array}$ & $\begin{array}{l}\text { 5-XII-39 } \\
\text { 5-I-40 } \\
\text { 9-II } \\
\text { 19-III } \\
-\end{array}$ & $\begin{array}{l}12-X I I-39 \\
\text { 5-I-40 } \\
\text { 9-II } \\
\text { 9-III } \\
\text { 15-IV }\end{array}$ & $\begin{array}{l}\text { A } \\
\text { B } \\
\text { C } \\
\text { D } \\
\text { E }\end{array}$ \\
\hline
\end{tabular}




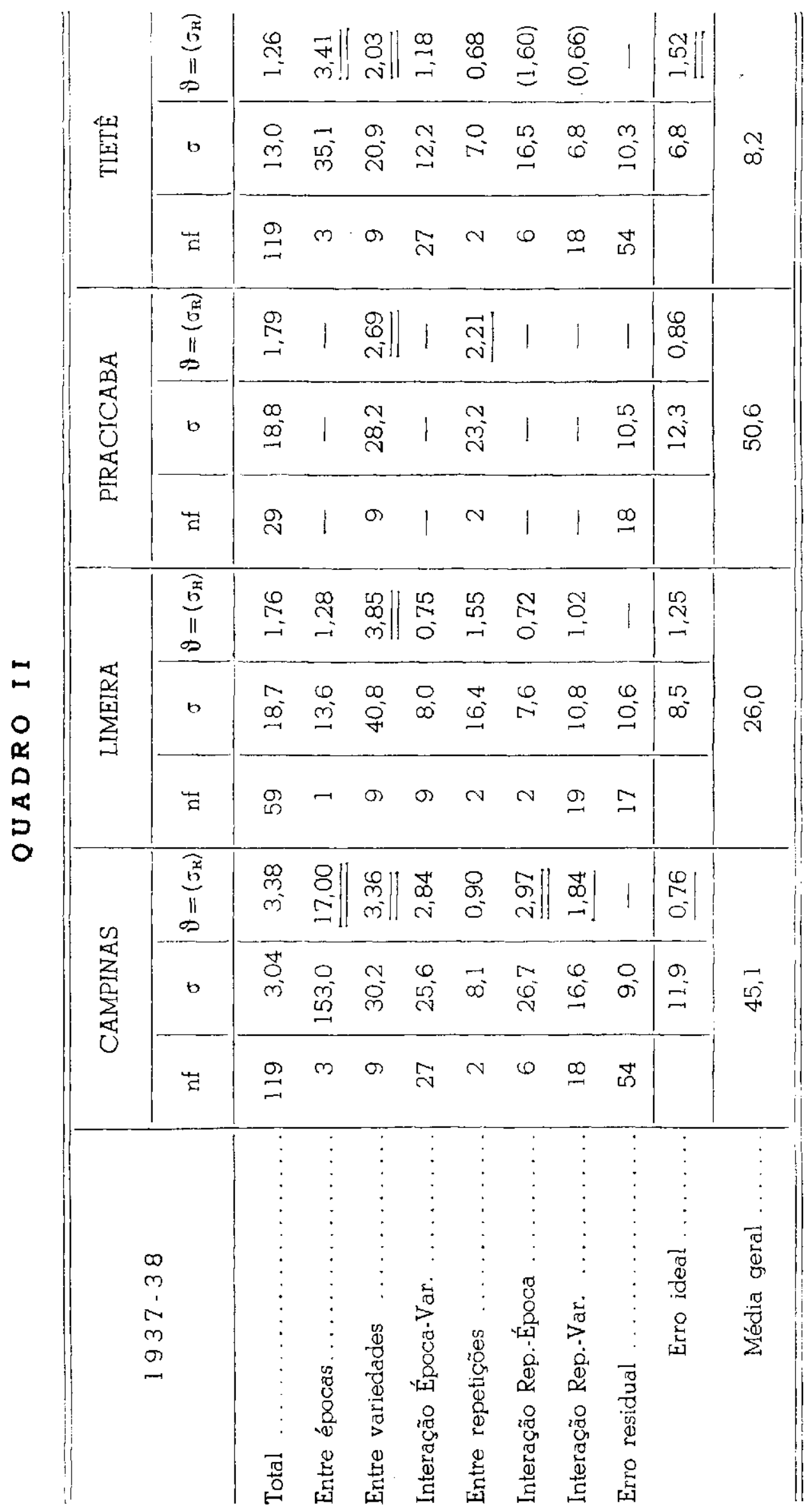




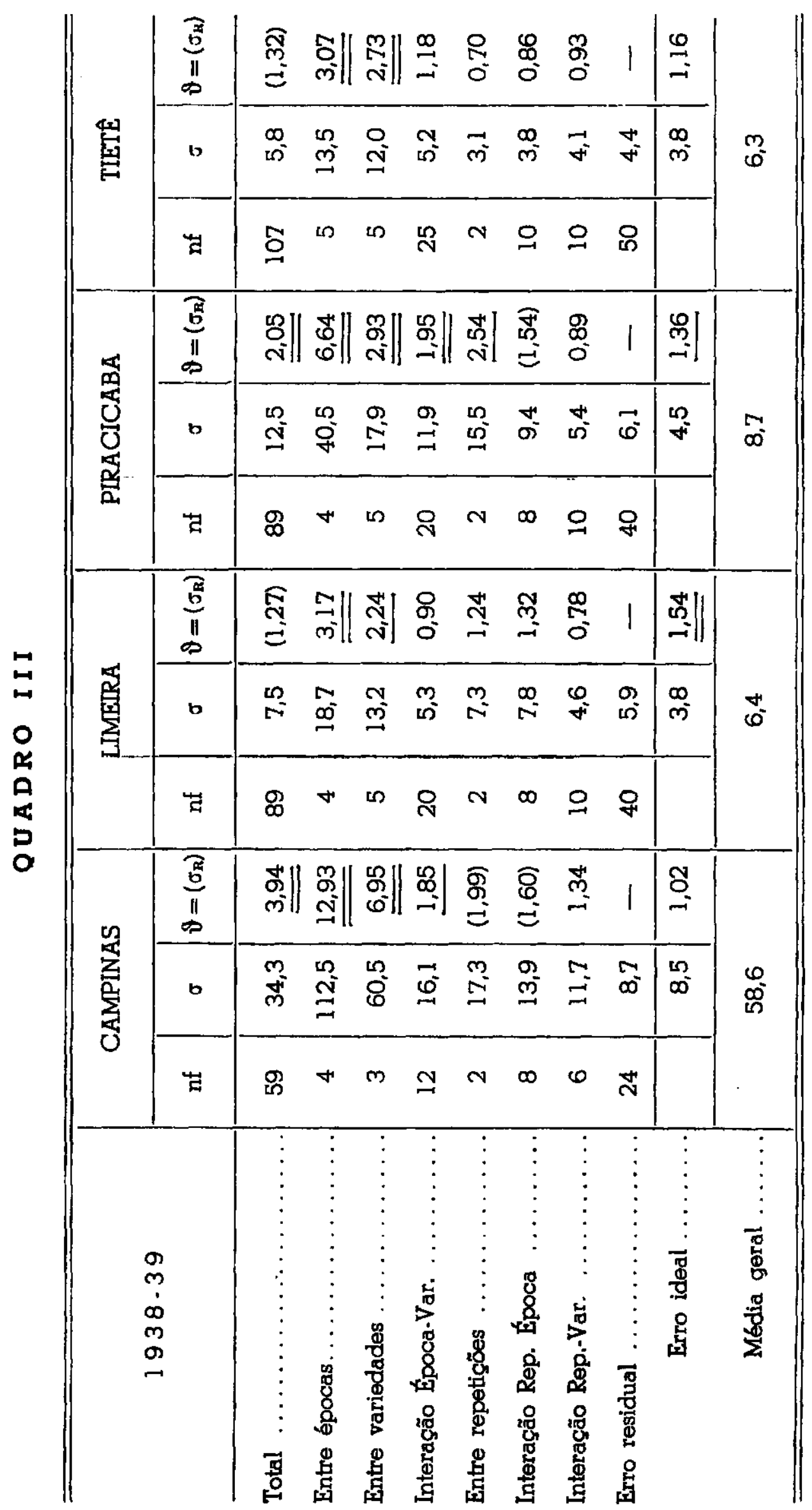




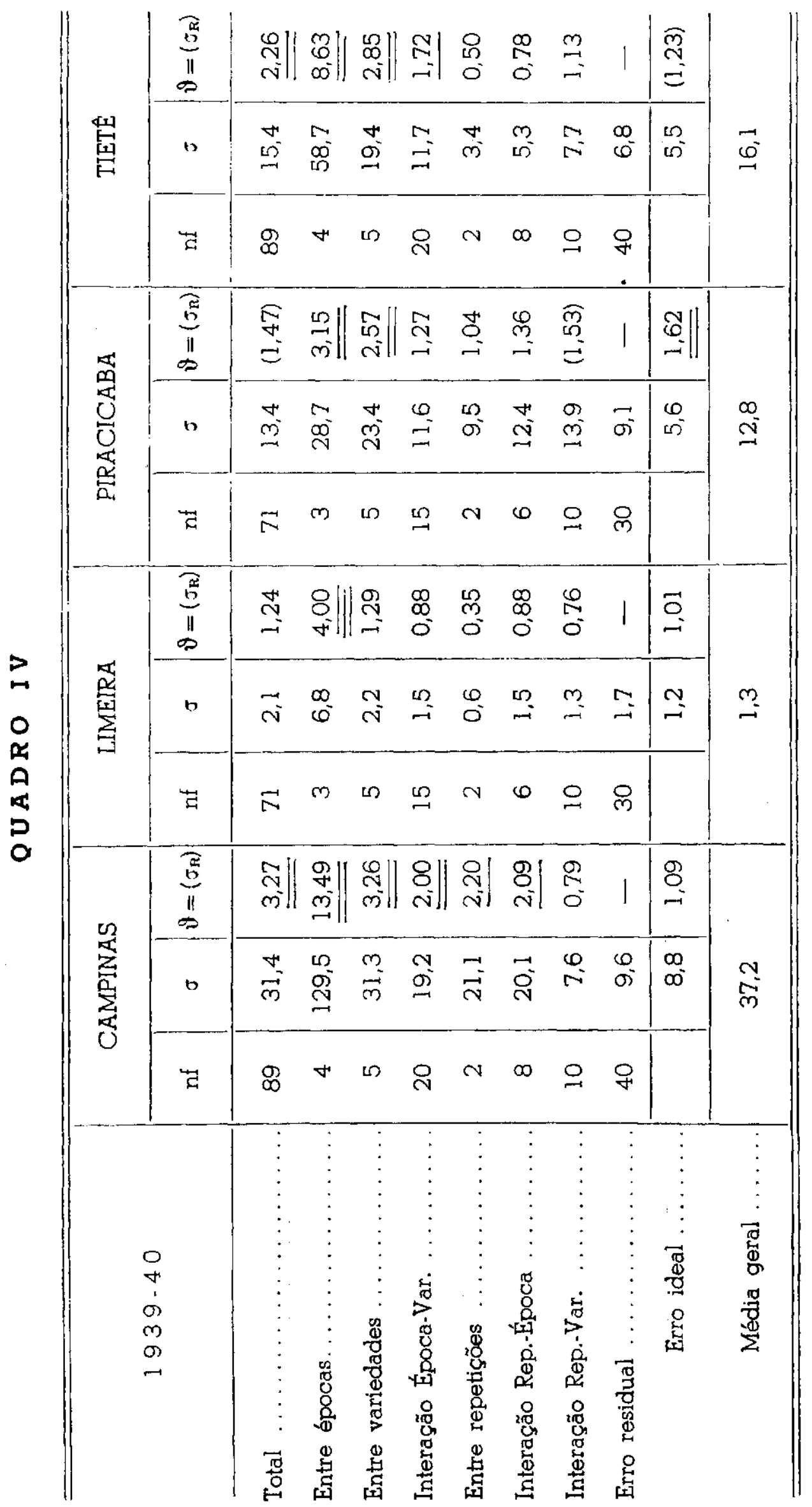


VoL. II

$1937 / 38$

QUADRO V

\begin{tabular}{|c|c|c|c|c|c|c|c|c|}
\hline \multirow{2}{*}{ VARIEDADES } & \multicolumn{2}{|c|}{ CAMPINAS } & \multicolumn{2}{|c|}{ LIMEIRA } & \multicolumn{2}{|c|}{ PIRACICABA } & \multicolumn{2}{|c|}{ TIETE } \\
\hline & $\begin{array}{l}\text { "Stand" } \\
\text { médio }\end{array}$ & $\begin{array}{c}\text { Vira- } \\
\text { cabeça } \\
\%\end{array}$ & $\begin{array}{l}\text { "Stand" } \\
\text { médio }\end{array}$ & $\begin{array}{c}\text { Vira- } \\
\text { cabeça } \\
\%\end{array}$ & $\begin{array}{l}\text { "Stand" } \\
\text { médio }\end{array}$ & $\begin{array}{c}\text { Vira- } \\
\text { cabeça } \\
\%\end{array}$ & $\begin{array}{l}\text { "Stand" } \\
\text { médio }\end{array}$ & $\begin{array}{c}\text { Vira. } \\
\text { cabeça } \\
\%\end{array}$ \\
\hline $\begin{array}{r}1 \\
33 \\
68 \\
73 \\
75 \\
121 \\
141 \\
142 \\
147 \\
163\end{array}$ & $\begin{array}{l}18,6 \\
17,3 \\
17,6 \\
17,1 \\
17,1 \\
16,9 \\
17,5 \\
18,2 \\
17,3 \\
17,5\end{array}$ & $\begin{array}{l}32,3 \\
53,4 \\
60,7 \\
43,4 \\
50,2 \\
46,8 \\
40,4 \\
34,4 \\
40,9 \\
49,0\end{array}$ & $\begin{array}{l}28,0 \\
24,0 \\
23,5 \\
28,5 \\
27,2 \\
26,5 \\
26,5 \\
28,2 \\
23,7 \\
27,8\end{array}$ & $\begin{array}{l}18,4 \\
27,1 \\
70,9 \\
16,4 \\
28,2 \\
33,3 \\
30,2 \\
11,8 \\
11,7 \\
18,6\end{array}$ & $\begin{array}{l}22,3 \\
11,3 \\
10,7 \\
22,3 \\
11,0 \\
21,0 \\
17,0 \\
12,3 \\
16,0 \\
22,0\end{array}$ & $\begin{array}{l}22,4 \\
58,8 \\
81,2 \\
62,7 \\
48,5 \\
61,9 \\
54,9 \\
32,4 \\
50,0 \\
45,4\end{array}$ & $\begin{array}{l}21,0 \\
16,3 \\
12,4 \\
14,3 \\
15,2 \\
16,6 \\
17,8 \\
15,1 \\
14,8 \\
20,2\end{array}$ & $\begin{array}{r}5,6 \\
16,8 \\
22,2 \\
7,6 \\
12,0 \\
5,0 \\
7,5 \\
3,9 \\
1,1 \\
4,1\end{array}$ \\
\hline $\begin{array}{l}\text { Número de } \\
\text { parcelas } \\
\text { Erro da média } \\
\text { por variedade }\end{array}$ & \multicolumn{2}{|c|}{12} & \multicolumn{2}{|c|}{6} & \multicolumn{2}{|c|}{ $\pm 6,07$} & \multicolumn{2}{|c|}{12} \\
\hline \multicolumn{9}{|l|}{ Épocas } \\
\hline III & $\begin{array}{r}27,1 \\
28,1 \\
6,3 \\
8,5\end{array}$ & $\begin{array}{r}22,6 \\
59,6 \\
100,0 \\
28,5\end{array}$ & $\begin{array}{l}\overline{26,3} \\
26,8 \\
-\end{array}$ & $\begin{array}{l}\overline{27,7} \\
24,2 \\
-\end{array}$ & $\begin{array}{l}16,6 \\
- \\
-\end{array}$ & $\begin{array}{l}50,6 \\
=\end{array}$ & $\begin{array}{l}18,2 \\
23,4 \\
12,5 \\
11,3\end{array}$ & $\begin{array}{r}2,0 \\
6,5 \\
10,9 \\
18,3\end{array}$ \\
\hline $\begin{array}{c}\text { Número de } \\
\text { parcelas } \\
\text { Erro da média } \\
\text { por época }\end{array}$ & \multicolumn{2}{|c|}{30} & \multicolumn{2}{|c|}{30} & \multicolumn{2}{|c|}{30} & \multicolumn{2}{|c|}{30} \\
\hline Total .... & 17,5 & 45,1 & 26,6 & 26,0 & 16,6 & 50,6 & 16.4 & 8,2 \\
\hline $\begin{array}{c}\text { Número de } \\
\text { parcelas } \\
\text { Erro da média } \\
\text { geral }\end{array}$ & \pm & 0,82 & \pm & 1,37 & \pm 1 & 1,92 & & 0,95 \\
\hline
\end{tabular}


$1938 / 39$

QUADRO VI

\begin{tabular}{|c|c|c|c|c|c|c|c|c|}
\hline \multirow{2}{*}{ VARIEDADES } & \multicolumn{2}{|c|}{ CAMPINAS } & \multicolumn{2}{|c|}{ LIMEIRA } & \multicolumn{2}{|c|}{ PIRACICABA } & \multicolumn{2}{|c|}{ TIETE } \\
\hline & 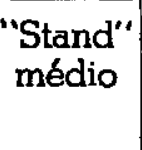 & $\begin{array}{c}\text { Vira- } \\
\text { cabeça } \\
\%\end{array}$ & $\begin{array}{l}\text { "Stand" } \\
\text { médio }\end{array}$ & $\begin{array}{c}\text { Vira- } \\
\text { cabeça } \\
\%\end{array}$ & $\begin{array}{l}\text { "Stand" } \\
\text { médio }\end{array}$ & $\begin{array}{c}\text { Vira- } \\
\text { cabeça } \\
\%\end{array}$ & $\begin{array}{l}\text { "Stand" } \\
\text { médio }\end{array}$ & $\begin{array}{c}\text { Vira- } \\
\text { cabeça } \\
\%\end{array}$ \\
\hline $\begin{array}{r}1 \\
14 \\
33 \\
38 \\
70 \\
142\end{array}$ & $\begin{array}{l}34,8 \\
31,7 \\
34,9 \\
32,3 \\
-\end{array}$ & $\begin{array}{l}61,1 \\
\overline{72,8} \\
36,9 \\
65,2 \\
-\end{array}$ & $\begin{array}{l}41,0 \\
36,7 \\
41,1 \\
41,4 \\
42,1 \\
42,6\end{array}$ & $\begin{array}{l}9,1 \\
9,8 \\
8,9 \\
1,1 \\
5,8 \\
4,1\end{array}$ & $\begin{array}{l}41,1 \\
37,8 \\
38,5 \\
41,6 \\
40,2 \\
38,9\end{array}$ & $\begin{array}{r}9,1 \\
14,6 \\
11,8 \\
1,1 \\
9,3 \\
7,0\end{array}$ & $\begin{array}{l}41,1 \\
39,6 \\
41,6 \\
40,6 \\
41,9 \\
41,9\end{array}$ & $\begin{array}{r}5,1 \\
10,4 \\
7,7 \\
2,2 \\
7,7 \\
4,9\end{array}$ \\
\hline $\begin{array}{l}\text { Número de } \\
\text { parcelas } \\
\text { Erro da média } \\
\text { por variedade }\end{array}$ & \multicolumn{2}{|c|}{ $\pm 2,25$} & \multicolumn{2}{|c|}{ $\pm 1,52$} & \multicolumn{2}{|c|}{ $\pm 1,57$} & \multicolumn{2}{|c|}{ $\pm 1,03$} \\
\hline $\begin{array}{c}\text { Épocas } \\
\text { I } \\
\text { III } \\
\text { IV } \\
\text { V } \\
\text { VI }\end{array}$ & $\begin{array}{l}40,4 \\
28,2 \\
24,7 \\
35,9 \\
37,9 \\
-\end{array}$ & $\begin{array}{l}92,0 \\
94,1 \\
34,1 \\
27,2 \\
42,2 \\
-\end{array}$ & $\begin{array}{l}47,3 \\
43,9 \\
38,4 \\
37,0 \\
37,4 \\
-\end{array}$ & $\begin{array}{r}6,5 \\
13,3 \\
1,7 \\
5,6 \\
3,9 \\
-\end{array}$ & $\begin{array}{l}46,9 \\
30,9 \\
36,4 \\
43,6 \\
40,6 \\
-6\end{array}$ & $\begin{array}{r}12,3 \\
25,7 \\
7,3 \\
1,4 \\
0,7 \\
\end{array}$ & $\begin{array}{l}46,1 \\
47,3 \\
46,1 \\
30,6 \\
47,6 \\
29,5\end{array}$ & $\begin{array}{r}4,6 \\
10,1 \\
7,7 \\
1,4 \\
4,2 \\
9,2\end{array}$ \\
\hline $\begin{array}{l}\text { Número de } \\
\text { parcelas } \\
\text { Erro da média } \\
\text { por época }\end{array}$ & \multicolumn{2}{|c|}{12} & \multicolumn{2}{|c|}{18} & \multicolumn{2}{|c|}{ $\pm 1,43$} & \multicolumn{2}{|c|}{18} \\
\hline Total & 33,4 & 58,6 & 40,8 & 6,4 & 39,7 & 8,7 & 41,2 & 6,3 \\
\hline $\begin{array}{c}\text { Número de } \\
\text { parcelas } \\
\text { Erro da média } \\
\text { geral }\end{array}$ & \pm 1 & .13 & \pm &, 62 & & 0,64 & & 0,42 \\
\hline
\end{tabular}


$1939 / 40$

QUADRO VII

\begin{tabular}{|c|c|c|c|c|c|c|c|c|}
\hline \multirow{2}{*}{ VARIEDADES } & \multicolumn{2}{|c|}{ CAMPINAS } & \multicolumn{2}{|c|}{ LIMEIRA } & \multicolumn{2}{|c|}{ PIRACICABA } & \multicolumn{2}{|c|}{ TIETE } \\
\hline & $\begin{array}{l}\text { "Stand" } \\
\text { médio }\end{array}$ & $\begin{array}{c}\text { Vira- } \\
\text { cabeça } \\
\%\end{array}$ & $\begin{array}{l}\text { "Stand" } \\
\text { médio }\end{array}$ & $\begin{array}{c}\text { Vira. } \\
\text { cabeça } \\
\%\end{array}$ & 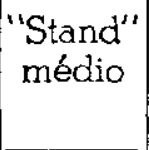 & $\begin{array}{c}\text { Vira- } \\
\text { cabeça } \\
\%\end{array}$ & $\begin{array}{l}\text { "Stand" } \\
\text { médio }\end{array}$ & $\begin{array}{c}\text { Vira- } \\
\text { cabeça } \\
\%\end{array}$ \\
\hline $\begin{array}{r}1 \\
14 \\
33 \\
38 \\
70 \\
142\end{array}$ & $\begin{array}{l}33,8 \\
22,5 \\
33,4 \\
32,9 \\
29,1 \\
30,2\end{array}$ & $\begin{array}{l}39,2 \\
35,0 \\
45,5 \\
27,3 \\
46,1 \\
29,4\end{array}$ & $\begin{array}{l}44,7 \\
43,7 \\
43,9 \\
42,9 \\
44,2 \\
43,8\end{array}$ & $\begin{array}{l}1,5 \\
1,1 \\
1,0 \\
0,4 \\
2,3 \\
1,3\end{array}$ & $\begin{array}{l}5,1 \\
6,3 \\
4,6 \\
1,0 \\
7,2 \\
2,8\end{array}$ & $\begin{array}{r}12,7 \\
19,3 \\
15,1 \\
2,6 \\
20,0 \\
8,2\end{array}$ & $\begin{array}{l}45,6 \\
41,3 \\
45,2 \\
44,7 \\
45,3 \\
44,9\end{array}$ & $\begin{array}{r}14,5 \\
23,9 \\
19,0 \\
8,8 \\
16,8 \\
14,3\end{array}$ \\
\hline $\begin{array}{l}\text { Número de } \\
\text { parcelas } \\
\text { Erro da média } \\
\text { por variedade }\end{array}$ & \multicolumn{2}{|c|}{ $\pm 2,49$} & \multicolumn{2}{|c|}{ $\pm 0,48$} & \multicolumn{2}{|c|}{ $\pm 2,63$} & \multicolumn{2}{|c|}{ $\pm 1,76$} \\
\hline \multicolumn{9}{|l|}{ Épocas } \\
\hline $\begin{array}{l}\text { I } \\
\text { II } \\
\text { III } \\
\text { IV }\end{array}$ & $\begin{array}{l}47,3 \\
46,1 \\
27,3 \\
16,4 \\
14,4\end{array}$ & $\begin{array}{r}3,3 \\
36,1 \\
58,9 \\
55,4 \\
90,0\end{array}$ & $\begin{array}{l}46,2 \\
45,9 \\
45,3 \\
37,9 \\
-\end{array}$ & $\begin{array}{l}0,5 \\
0,8 \\
3,6 \\
- \\
-\end{array}$ & $\begin{array}{l}3,3 \\
4,9 \\
7,7 \\
2,2 \\
\end{array}$ & $\begin{array}{l}7,6 \\
16,7 \\
20,5 \\
7,0 \\
-\end{array}$ & $\begin{array}{l}47,2 \\
41,2 \\
46,3 \\
43,7 \\
44,1\end{array}$ & $\begin{array}{r}1,9 \\
19,5 \\
16,7 \\
6,2 \\
37,3\end{array}$ \\
\hline $\begin{array}{l}\text { Número de } \\
\text { parcelas } \\
\text { Erro da média } \\
\text { por época }\end{array}$ & \multicolumn{2}{|c|}{ $\pm 2,27$} & \multicolumn{2}{|c|}{ $\pm 0,39$} & \multicolumn{2}{|c|}{ $\pm 2,15$} & \multicolumn{2}{|c|}{ $\pm 1,61$} \\
\hline Total & 30,3 & 37,2 & 43,8 & 1,3 & 4,5 & 12,8 & 44,5 & 16,1 \\
\hline $\begin{array}{c}\text { Número de } \\
\text { parcelas } \\
\text { Erro da média } \\
\text { geral }\end{array}$ & \pm & .01 & & 0,20 & \pm & 1,08 & \pm & 0.72 \\
\hline
\end{tabular}

